\title{
PARASITIC INFECTIONS OF THE GILLS OF WILD AFRICAN SHARPTOOTH CATFISH (CLARIAS GARIEPINUS)
}

\author{
MAHMOUD MOSTAFA MAHMOUD ${ }^{1}$; EBTSAM SAYED HASSAN ${ }^{1}$; MOHIE HARIDY ${ }^{2}$; \\ ESSAM ALI NOUR EL DEEN ${ }^{2}$; HUDA MOHAMMED M. KURAA ${ }^{3}$ and HEBA NAEIM SADEK \\ HANNA $^{3}$ \\ ${ }^{1}$ Department of Aquatic Animals Medicine and Management, Faculty of Veterinary Medicine, \\ Assiut University, Assiut, Egypt \\ ${ }^{2}$ Faculty of Veterinary Medicine, South Valley University, Qena, Egypt \\ ${ }^{3}$ Animal Health Research Institute, Assiut, Egypt.
}

Received: 28 June 2018; Accepted: 24 July 2018

\begin{abstract}
A one-year study (January to December 2015) was conducted to identify the various parasites that infect the gills of African sharptooth catfish, Clarias gariepinus. Two hundred and forty fish (20 fish/ month) of different sexes and sizes were collected from the River Nile and its tributaries at Assiut Province, Egypt. Fish were subject to clinical and parasitological examinations. The protozoan and metazoan parasites found included Trichodina sp., Henneguya sp., Myxobolus sp., monogenean trematodes and encysted metacercariae (E.M.C) of digenean trematodes. The infection rates for these parasites were $14.1 \%, 32.0 \%, 5.8 \%, 22.0 \%$ and $4.2 \%$, respectively. Mixed infections with more than one type of parasite was observed in $17.1 \%$, while single infection was seen in $43.8 \%$ of the fish examined. The highest rate of infection was observed during the winter and spring seasons (68.3\% and $60.0 \%$ respectively), while in the summer and autumn seasons the rates were $58.3 \%$ and $55.0 \%$ respectively. The total infection rates in females were insignificantly higher than in males. The infection rates were lower in larger fish. The histopathological alterations induced by the parasites, herein, represented mainly in hyperplasia of gill filaments, partial or complete sloughing of the lining epithelium, focal chondritis and submucosal vasculitis with mononuclear cell infiltration.
\end{abstract}

Keywords: gill parasites, infection rates, histopathology, Clarias gariepinus

\section{INTRODUCTION}

African sharptooth catfish, Clarias gariepinus, is one of the popular fish species that inhabit the River Nile and its tributaries. In their natural habitats, fish may suffer from various diseases including parasitic infections (Bamidele, 2015). Parasitic diseases of fish are common all over the world and are of particular importance in the tropics (Roberts and Janovy, 2009). Parasites affect fish health, growth and survival causing economic losses in aquaculture (Marzouk et al., 2013). Also, some fish parasites have zoonotic importance as eating raw, or improperly cooked fish causes diseases to human that have been reported from different geographical areas worldwide (Mahmoud, 2006 and Park et al., 2009).

Corresponding author: Dr. MAHMOUD MOSTAFA

E-mail address: mahmoud88@aun.edu.eg mahmoud88@hotmail.com

Present address: Department of Aquatic Animals Medicine and Management, Faculty of Veterinary Medicine, Assiut University, Assiut, Egypt
Previous studies have been conducted to explore the different parasites infecting various fish species in Egypt (Amina and Bashter, 2002; Eissa et al., 2006; El-Seify et al., 2011; Marzouk et al., 2013 and Noor El- Deen et al., 2015). Parasitic infections of $C$. gariepinus have drawn the attention of many researchers (Arafa et al., 2009; Bichi and Yelwa, 2010; Saleh, 2010; Omeji et al., 2011; Saleh, 2015 and Tachia et al., 2013). Also, the parasitic infections of fish gills (Diab et al., 2006; Bichi and Yelwa, 2010 and Eissa et al., 2014) have been addressed.

However, due to the impact of many limiting factors (e.g. climate, locality, time of sampling, fish size, sex and species) on the incidence, prevalence and distribution of the fish parasites, the present work aims to investigate the parasites infecting the gills of C. gariepinus with different sizes and sexes in certain locality of River Nile and its tributaries (Assiut Governorate) at different seasons of the year. Also, the pathological effects of these parasites on fish have been studied. 


\section{MATERIALS AND METHODS}

\section{Sample collection:}

Two hundred and forty live African sharptooth catfish, Clarias gariepinus of different sizes and sexes were randomly collected from the River Nile and its tributaries at Assiut Governorate during different seasons (20 fish/ month) over one year starting from January till December 2015. Fish were immediately transported to the laboratory of Aquatic Animals Medicine and Management, Faculty of Veterinary Medicine, Assiut University to perform the clinical and parasitological examinations. All data about the fish specimens as the date of collection, body weight, standard length and sex of fish were recorded.

\section{Clinical and parasitological examinations:}

Fish were directly examined for any apparent clinical signs, lesions or abnormalities according to the methods described by Noga (2010). Gills and suprabranchial (extra respiratory) organs were examined grossly for any cyst or macroscopic parasites. Consequently, gill mounts were prepared and examined microscopically. Also, Giemsa-stained preparations were examined under oil immersion lens. For cysts, both wet- and stained- preparations of the excised cysts were examined and the internal contents were photographed. Examination and identification of the myxozoan parasites were performed following the method described by Fomena and Bonix (1997).

The infection rate of each parasite, its correlation with different seasons, fish sizes or sexes was calculated.

\section{Histopathological examination:}

Specimens from the gills and extra respiratory organs were prepared for histopathological examination as described by Bancroft and Stevens (1996). Briefly, specimens were fixed in $10 \%$ neutral buffered formalin solution, then embedded in paraffin, sectioned $(5 \mu \mathrm{m})$ and stained with hematoxylin and eosin.

\section{Statistical analysis:}

One-way, two-way ANOVA and $t$-test were used to analyze the data. Infection rates were calculated as the number of infected/ total number of examined fish $\times$ 100. All analyses were performed using the software Programmed Graph Pads Prism ${ }^{\circledR} 5$ software (version 5.01).

\section{RESULTS}

\section{Clinical and parasitological examinations:}

No specific clinical signs were observed on fish inspected. However, general signs including skin erosions, ulcers, fin rot were detected on fish examined. Also, gills of some infected fish appeared pale in color and covered with excessive mucus, while in other fish they were congested and swollen.

The parasitological examination of gills and respiratory organs revealed the presence of Trichodina sp., Henneguya sp., Myxobolus sp., monogenetic trematodes or encysted metacercariae (E.M.C) of digenetic trematodes (Fig.1 and 2).

Some fish had creamy white ovoid to round cysts in extra respiratory organs (Fig. 3). When opened, these cysts released creamy white viscous milky fluid containing a great number of microscopic spores of Henneguya sp.

The infection rates of Trichodina sp., Henneguya sp., Myxobolus sp., monogenetic trematodes and E.M.C were $14.1 \%, 32.0 \%, 5.8 \%, 22.0 \%$ and $4.2 \%$, respectively (Fig. 4). Significant differences were found among different parasites infection rates. The total infection rate of all different gill parasites was $60.4 \%$.

Investigating the seasonal infection rates of the gill parasites revealed that the highest rate of infection was observed during the winter and spring with infection rates of $68.3 \%$ and $60.0 \%$ respectively, while summer and autumn showed moderate rates (58.3\% and 55.0\%) respectively (Fig. 5).

Different sexes exhibited insignificant difference, where mean infection rate in males was $55.5 \%$ and in females was $65.3 \%$ (Fig. 6).

Small-sized fish (17-32 cm) displayed an insignificant higher infection rate $(61.7 \%)$ when compared with that of large-sized fish $(33-42 \mathrm{~cm})$ which exhibited an infection rate of $58.9 \%$ (Fig. 7).

\section{Histopathological examination:}

Gills infested with Trichodina sp. showed ulceration and hyperplasia of the lining epithelium (Fig. 8). Extra respiratory organ infected with Henneguya sp. cyst revealed hyperplasia of the lining epithelium, focal chondritis and submucosal vasculitis with mononuclear cell infiltration (Fig. 9). Gill filament infected with Myxobolus sp. revealed necrosis and ulceration of remnant epithelium (Fig. 10). While, the gill filament infested with monogenes displayed hyperplasia of lining epithelium, macrophage and fibroblastic proliferation in primary lamellae core and destruction of the cartilaginous plate with hyperplasia of chondrocytes forming focal areas of chondritis (Fig. 11). On the other hand, the gill filaments infected with EMC exhibited thickening of the primary and secondary lamellae with hyperplasia of the lining epithelium (Fig. 12). 


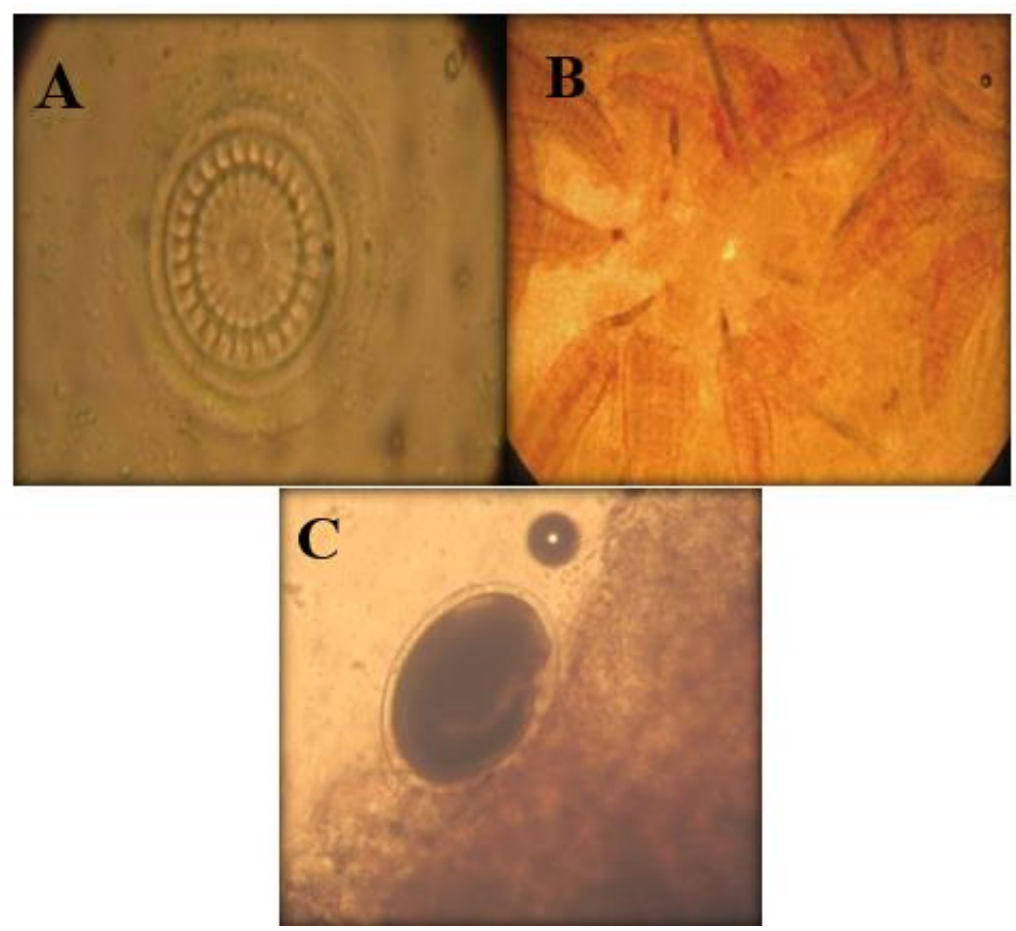

Fig. 1: Wet mount of gills of Clarias gariepinus showing: (A) Trichodina sp. $(\times 40)$, (B) Monogeneans $(\times 10)$ and (C) encysted metacercaria $(\times 40)$.

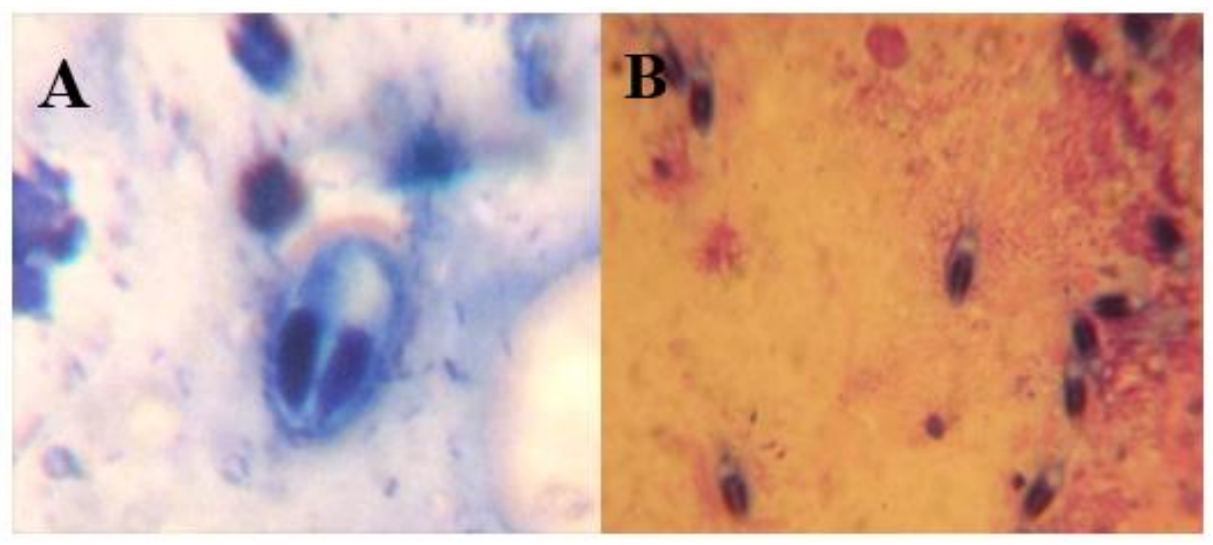

Fig. 2: Gill smear stained with Giemsa stain showing: (A) Myxobolus sp. (B) Sperm-like spores of Henneguya sp., released from cysts $(\times 100)$

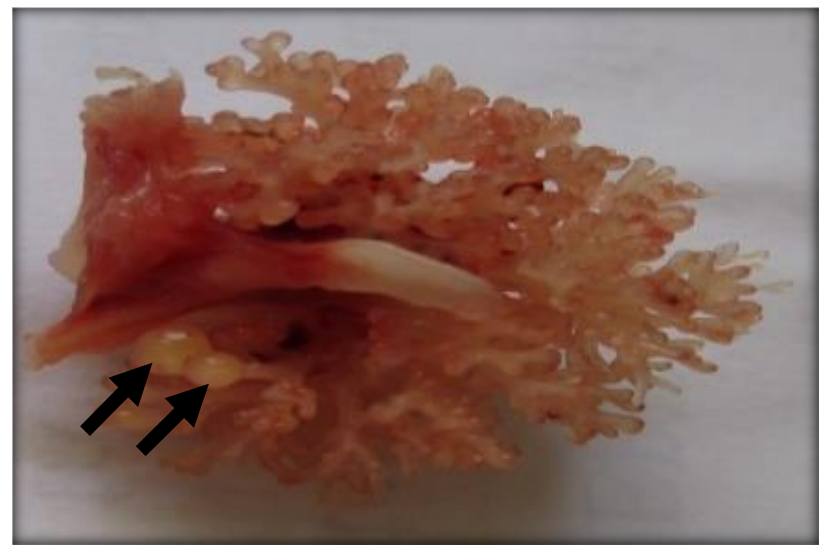

Fig. 3: An Extra-respiratory organ of Clarias gariepinus with creamy white ovoid to round-shaped cysts (arrows). 


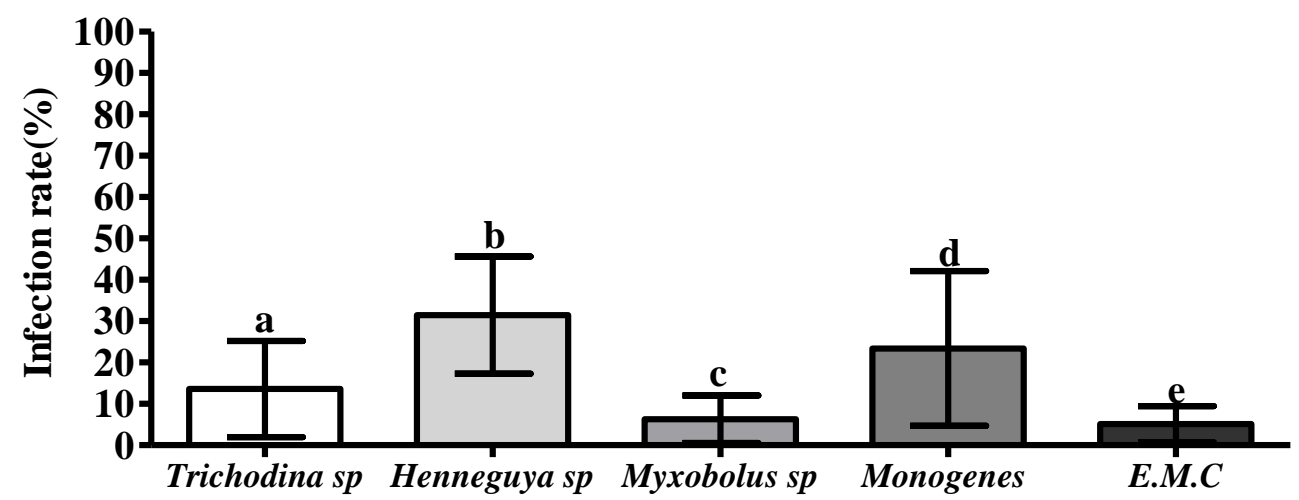

Fig. 4: Infection rates of Clarias gariepinus with gill parasites. Columns represent the total infection rate (Mean $\pm \mathrm{SD})$ for each parasite. Different letters indicate significant difference $(P<0.0001)$. E.M.C: Encysted Metacercariae.

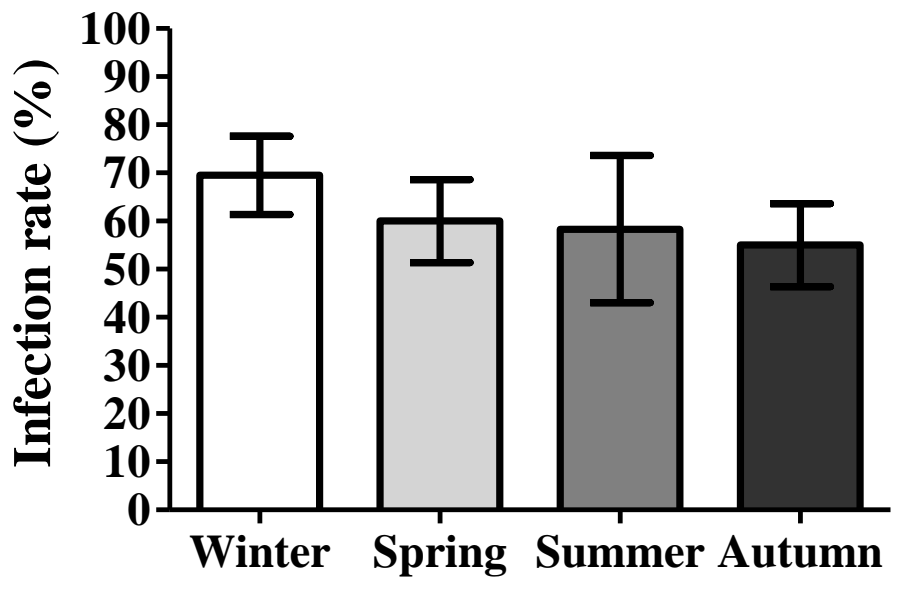

Season

Fig. 5: Seasonal infection rates of Clarias gariepinus with gill parasites. Columns represent the total infection rate (Mean $\pm \mathrm{SD})$. There were no significant differences among the different seasons $(P>0.05)$.

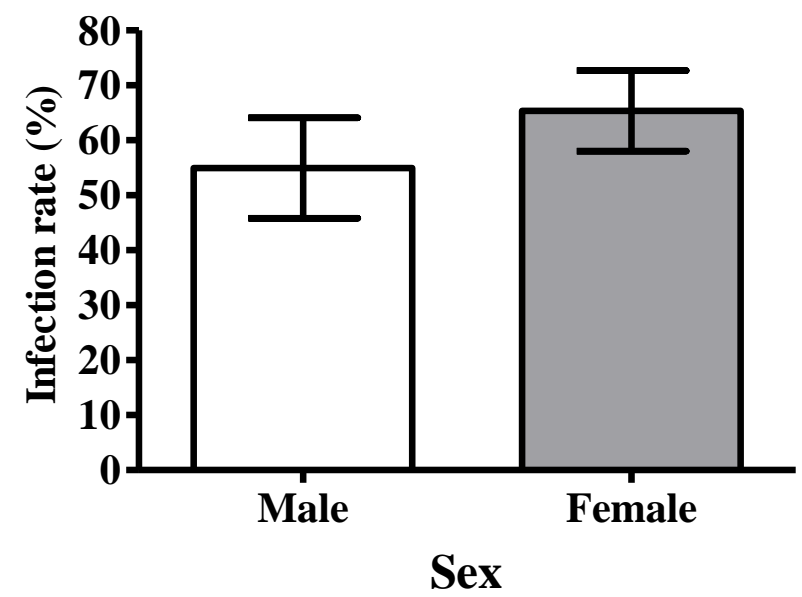

Fig. 6: Infection rates of Clarias gariepinus with gill parasites in different fish sexes. Columns represent the total infection rate (Mean $\pm \mathrm{SD}$ ). There was no significant difference between groups $(P>0.05)$. 


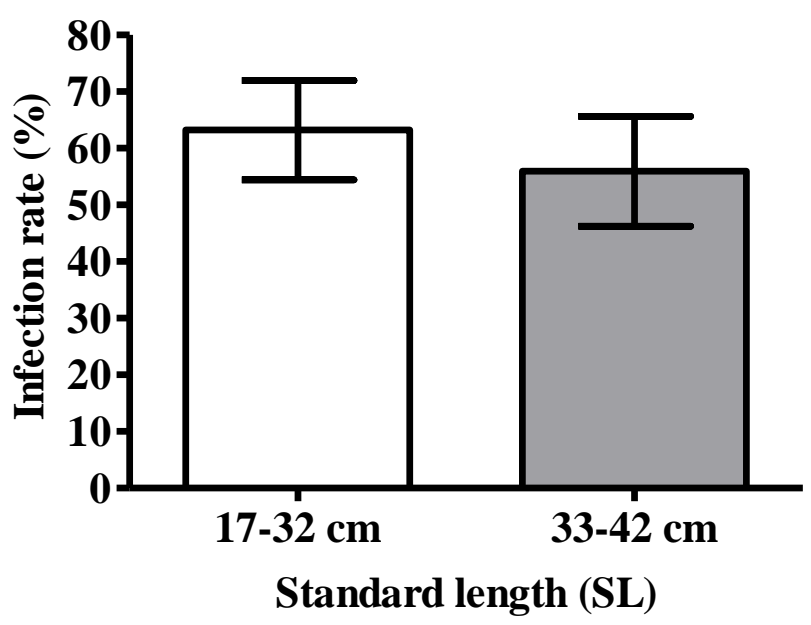

Fig. 7: Infection rates of Clarias gariepinus with gill parasites in different fish sizes (estimated from standard length). Columns represent the total infection rate (Mean \pm SD). There were no significant differences between groups $(P>0.05)$.

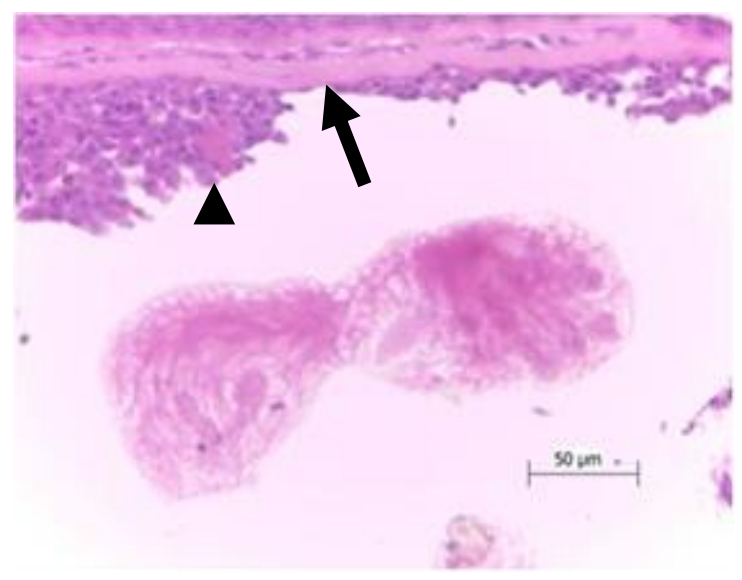

Fig. 8: Gills of Clarias gariepinus infested with Trichodina sp. showing ulceration (arrow) and hyperplasia of lining epithelium (arrowhead) $(\mathrm{H} \& \mathrm{E}, \mathrm{bar}=50 \mu \mathrm{m})$

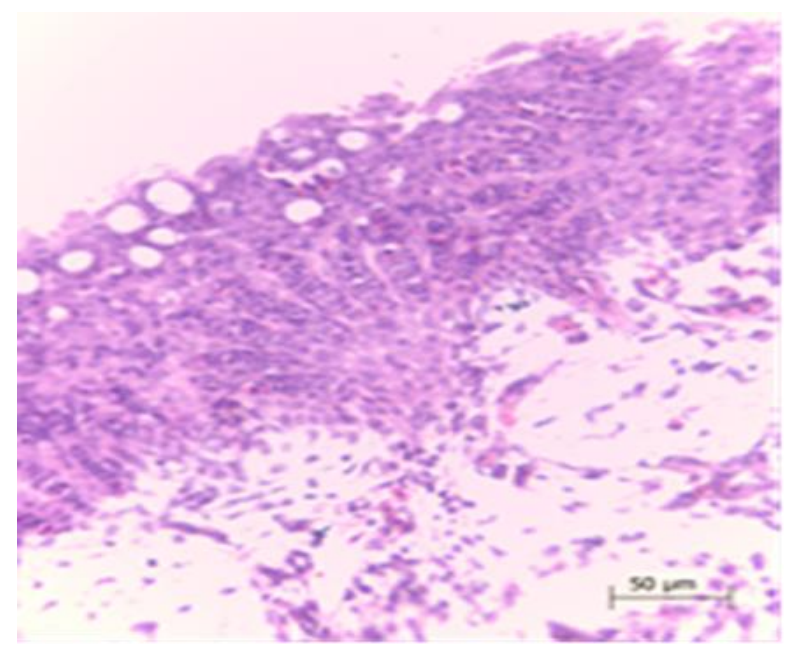

Fig. 9: Extra respiratory organ of Clarias gariepinus infected with Henneguya sp. cyst showing hyperplasia of remnant epithelium, focal chondritis and submucosal vasculitis with mononuclear cell infiltration $(\mathrm{H} \& \mathrm{E}$, bar $=$ $50 \mu \mathrm{m})$ 


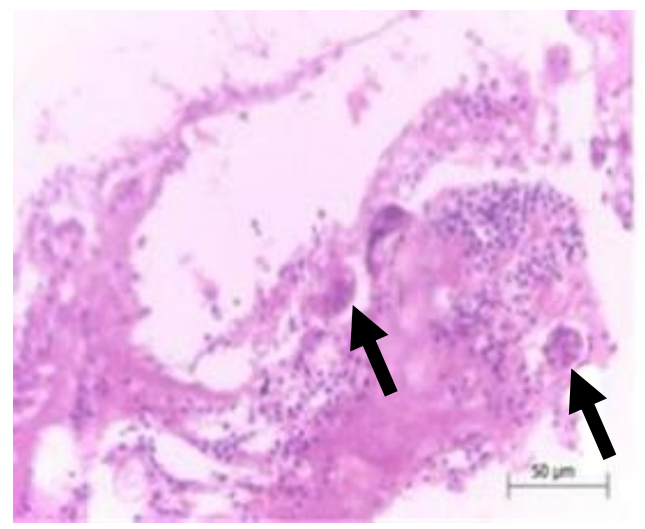

Fig. 10: Gill filament of Clarias gariepinus infected with Myxobolus sp. showing necrosis and ulceration of remnant epithelium. Necrotic tissue containing degenerated Myxobolus sp. parasites (arrows) $(\mathrm{H} \& \mathrm{E}, \mathrm{bar}=50$ $\mu \mathrm{m})$

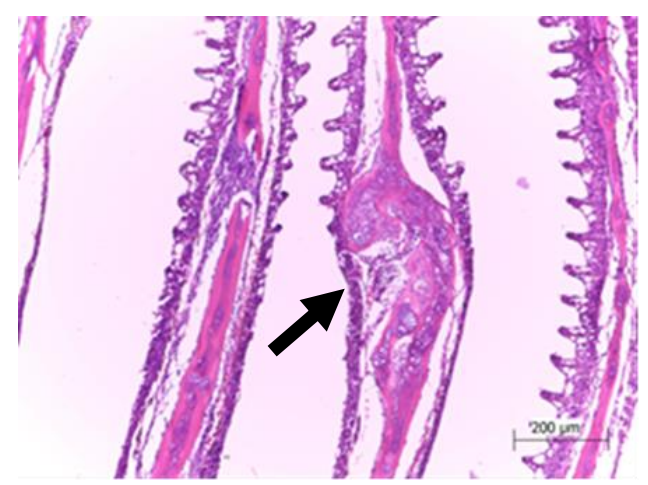

Fig. 11: Gill filament of Clarias gariepinus infested with monogenetic trematode showing the destruction of the cartilaginous plate with hyperplasia of chondrocytes forming focal areas of chondritis (arrow) (H\&E, bar $=200$ $\mu \mathrm{m})$

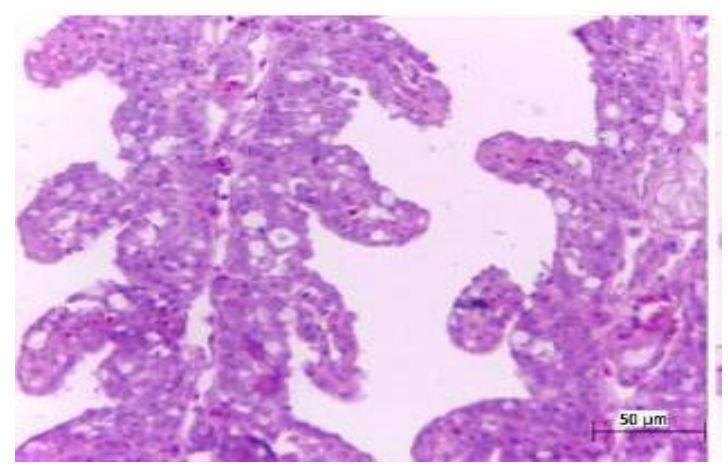

Fig. 12: Gill filaments of Clarias gariepinus infected with encysted metacercaria of digenetic trematode showing thickening of the primary and secondary lamellae with hyperplasia of the lining epithelium $(\mathrm{H} \& \mathrm{E}$, bar $=50 \mu \mathrm{m})$

\section{DISCUSSION}

Parasitic infection is a dangerous threat to the fish health and survival. Though many parasites do not induce acute mortalities, they still adversely affect the fish well-being and may predispose to other problems including bacterial or viral infections. Gill parasites are a potential cause of fish losses through hindering respiration leading to the fish kill. The current study investigated the various parasites infecting gills of African sharptooth catfish, C. gariepinus.

The total infection rate of gill parasites recorded in the present work was $60.4 \%$. This rate is lower than that reported by El-Nobi (1998) and Saleh (2010) who found that the overall infection rate was $86.8 \%$ in Abbassa, $85.0 \%$ in Assiut governorate respectively, but it was higher than that recorded by Diab et al. (2006), Emere and Egbe (2006) and Bichi and Yelwa 
(2010) who described the total infection rates of $44.4 \%, 17.7 \%$ and $12.2 \%$ in different localities and fish species respectively. These differences in infection rates among studies, including our own, may be due to ecological differences in sites from which the fish were collected where the effects of environmental conditions on the infection rates and parasites may be positive by accelerating the life cycle and increase parasitism or negative as it may be fatal for certain parasite species (Eissa et al., 2014). Also, immunosuppression is an important factor responsible for the high rates of parasitic diseases in fish. Skinner (1982) mentioned that chronic exposure to pollutants or any environmental stress which lead to immunosuppression through the release of corticosteroids make the fish more susceptible to parasites.

Among the parasites found in the present study, Henneguya sp. was the most common, with $32.0 \%$ infection rate. However, this finding is different from that of El-Seify et al. (2011) who reported that monogenetic trematodes represented the most prevalent among external parasites found. Since Clarias sp. is bottom dwellers, they feed on what is most available and close to them such as detritus, water invertebrates like arthropods, mollusks and mud (Imevbore and Bakare, 1970). These invertebrates may be intermediate hosts of myxozoan parasites. In addition, the increase in organic matter in the water may accelerate the life cycle of Henneguya sp. and this may explain why $C$. gariepinus exhibited an infection rate of Henneguya sp. that was higher than those for other parasites found.

Regarding the seasonal prevalence of infection, the present work revealed that the highest rates were observed during winter and spring $(68.3 \%$ and $60.0 \%$ ) respectively, while summer and autumn seasons exhibited lower rates $(58.3 \%$ and $55.0 \%)$ correspondingly. However, in their studies on Nile tilapia, Eissa et al. (2014) and Noor El- Deen et al. (2015) reported that the highest seasonal prevalence of gill parasites was in summer. The high infection rate in winter may be as a result of receding of water systems during this season which results in habitat shrinking and this may increase the proximity of host to the parasites or their intermediate host. Meanwhile, precipitation and the associated hydrodynamic changes may disrupt parasite transmission, thereby changing the infection patterns (Pech et al., 2010). In addition, cold temperature proved to decrease the immune response and diseases resistance in fish rendering them more liable to parasitic infection. Also, during winter, the fishes lose their appetite, results in stress condition and get easily affected by different diseases (Ananya et al., 2017).

The present investigation disclosed that female fish seems to be more susceptible to total gill parasites than males but with no significant difference. This sex-related pattern of infection may be due to the physiological state of females, as most gravid females have reduced resistance to infections by various organisms including parasites. Besides, their increased rate of food intake to meet their food requirements for the development of their eggs can expose them to more contact with the parasites, which subsequently increase their chances of being infected. Similar findings were stated previously (Emere and Egbe, 2006; Omeji et al., 2015 and Uruku and Adikwu, 2017). Also, Bichi and Yelwa (2010) reported that the females had a higher incidence rate of infection $(20.7 \%)$ than the males $(11.8 \%)$. These results, however, did not differ significantly $(P>0.05)$. On the other hand, Tachia et al. (2013) found a significant difference in ectoparasitic infections between the different sexes of $C$. gariepinus and the male fish had a higher infection rate than the female one.

The current study revealed that small-sized fish were more susceptible to gill parasites when compared with larger ones. This result may be attributed to the ill-developed immune system of smaller fish. However, Omeji et al. (2011) reported that bigger fishes had higher rates of parasitic infection than the smaller ones.

It is noteworthy that mixed infection with more than one type of parasite was observed in $17.1 \%$, while the single infection was detected in $43.8 \%$ of the fish examined in the current study. Multiple infections were common due to the fact that the environment supports several parasites species, thereby exposing the host to simultaneous infections with many of them. The presence of one parasite and its activity within the host weaken the resistance which makes concurrent infection feasible. So, the clinical pictures recorded in infected fish were not specific and could be resulted from several parasites.

Histopathology of gills infested with Trichodina sp. showed ulceration and hyperplasia of lining epithelium. These tissue changes may be due to the direct damage effect of the local parasite and its continuous irritation. Similar results were also reported by Aly et al. (1998). Extra-respiratory organs infected with Henneguya sp. revealed hyperplasia of the lining epithelium, focal chondritis, submucosal vasculitis with mononuclear cell infiltration. These alterations may be attributed to the pressure of the spores of Henneguya sp. on the host's tissue (Amina and Bashter, 2002). The gill filaments infected with Myxobolus sp. displayed necrosis and ulceration of remnant epithelium. These results were supported by those of Saleh (2015). These lesions may develop as a result of the direct contact between the parasite and the host tissues and the secretion of certain kinds of proteolytic enzymes by the parasites that liquefy the infected tissues and digest the cement 
material between the connective tissues and other tissues (Eissa et al., 2006). Also, the gill filaments infested with monogenes showed hyperplasia of lining epithelium, macrophage and fibroblastic proliferation in primary lamellae core and destruction of the cartilaginous plate with hyperplasia of chondrocytes forming focal areas of chondritis. These pathological changes may be due to the permanent irritating effect caused by the organ of fixation which usually leads to hyperplastic changes in the gills (Sterud et al., 1998; Noor El- Deen et al., 2015). Also, Arafa et al. (2009) reported similar results. While, the gill filaments infected with EMC, revealed thickening of the primary and secondary lamellae with hyperplasia of the lining epithelium. Shoaibi et al. (2010), recorded cartilage proliferation, hyperplasia, hypertrophy, and fusion of gill filament in platyfish infected with metacercaria. These alterations may result from the pressure of the cysts on the host's tissue.

\section{REFERENCES}

Aly, S.M.; Hassan, M.G. and Abd El-Aal, A.A. (1998): Studies on parasitic infections among freshwater fishes and their associated pathological lesion. Vet. Med. Zag. Congress 26-28 August in Hurghada.

Amina, E.M. and Bashter, A.R. (2002): Histopathological and ultrastructual studies of Henneguya suprabranchiae Landsberg, 1987 (Myxosprea: Myxobolidae) parasitizing the suprabranchial organ of the freshwater catfish Clarias gariepinus Burchell, 1822 in Egypt. Parasitol. Res. 88: 617-62.

Ananya, G.; Gadadhar, D.; Debapriyo, M.; Koel, B. and Prasenjit, M. (2017): Study of parasites from wild and cultured heteropneustes fossilis in selected districts of west Bengal IOSRJAVS. 10(7): 21-29.

Arafa, S.Z.; El-Naggar, M.M. and El-Abbassy, S.A. (2009): Mode of attachment and histopathological effects of Macrogyrodactylus clarii, a monogenean parasite of the catfish Clarias gariepinus, with a report on host response. Acta Parasit. 54: 103-112.

Bamidele, A. (2015): A two fish species study of the parasitic helminth fauna of Synodontis filamentosus (BOULENGER, 1901) and Calamoichthys calabaricus (SMITH, 1865) From Lekki Lagoon, Lagos, Nigeria. Ife J Sci., 17: 97-108.

Bancroft, J.D. and Stevens, A. (1996): Theory and Practice of Histological Technique. $4^{\text {th }}$ Ed., Churchill, Livingsto, New York, London, San Francisco, Tokyo.

Bichi, A.H. and Yelwa, S.I. (2010): Incidence of piscine parasites on the gills and gastrointestinal tract of Clarias gariepinus
(Teugels) at Bagauda fish farm, Kano, Bayero. J. pure appl. sci. technol. 3: $104-107$.

Diab, A.S.; El-Bouhy, Z.M. and Abdel-Hadi, Y.M. (2006): Prevalence of some parasitic agents affecting the gills of some cultured fishes in Sharkia, Damietta and Fayium Governorates, Zag. Vet. J. 34: 81-91.

Eissa, I.A.; Abu Mourad, I. and Borhan, T. (2006): A contribution on Myxosoma infection in cultured Oreochromis niloticus in Lower Egypt. Nat. Sci. 4: 40-46.

Eissa, I.A.; Ramadan, R.A.; Derwa, H.I.; Mona, I. and Nashwa, M. (2014): Studies on the prevailing gill parasitic diseases among cultured tilapia species in relation to some ecological factors. 4th Conference of CLAR, 237-248.

El-Nobi, G.A. (1998): Studies on the main parasitic diseases affecting cultured fish and its influences by some ecological factors. Ph.D. Thesis, Fac. Vet. Med. Zag. Univ.

El-Seify, M.A.; Zaki, M.S.; Abdel Razek, Y.D.; Hossam, H.A.; Osman, K.A. and Attia, A.A. (2011): Seasonal variations and prevalence of some external parasites affecting freshwater fishes reared at Upper Egypt. J. Life. Sci., 8: 397-400.

Emere, M.C. and Egbe, N.E. (2006): Protozoan parasites of Synodonits clarias (a freshwater fish in river Kaduna). BEST J. 3: 58-64.

Fomena, A. and Bonix, G. (1997): Myxosporea (Protozoa: Myxozoa) of freshwater fishes in Africa: Keys to genera and species. Syst. Parasitol. 37: 161-178.

Imevbore, A.M. and Bakare, O. (1970): The food and feeding habits of non-cichlid fishes of the River Niger in the Kainji Reservoir area. Ecology. 1: 49-64.

Mahmoud, E.A. (2006): Role played by fish in transmitting helminth human parasites. M. V. Sci. thesis. Faculty of Medicine, Assuit University.

Marzouk, M.S.; Mahdy, O.A.; El-Khatib, N.R. and Yousef, N.S. (2013): Contribution in ectoparasitic infection and its control in cultured Oreochromis niloticus in Egypt. AJRC, 1: 326-338.

Noga, E.J. (2010): Fish Disease, Diagnosis and Treatment. $2^{\text {nd }}$ Edition. Wiley-Blackwell: Singapore, pp. 519

Noor El- Deen, A.I.; Abd El Hady, O.K.; Kenawy, A.M. and Zaki, M.S. (2015): Study of prevailing external parasitic diseases in cultured freshwater Tilapia Oreochromis niloticus Egypt. J. Life Sci. 12: 30-37

Omeji, S.; Solomon, S.G. and Idoga, E.S. (2011): A Comparative study of the common protozoan parasites of Clarias gariepinus from the wild and cultured environments in Benue State, Nigeria. Parasitol. Res. pp 8.

Omeji, S.; Obande, R.A. and Member, S.T. (2015): Prevalence of endoparasites of Synodontis 
shcall and Synodontis ocellifer (upside-down catfish) from Lower River Benue, Nigeria. I.J. Anim. Biol., 5: 176-181.

Park, C.W.; Kim, J.S.; Joo, H.S. and Kim, J. (2009): A human case of Clinostomum complanatum infection in Korea. Korean J. Parasitol. 47: 401-404.

Pech, D.; Aguirre-Maceedo, M.L.; Lewis, J.W. and Vidal-Martinez, V.M. (2010): Rainfall induces time-lagged changes in the proportion of tropical aquatic hosts infected with metazoan parasites. Int. J. Parasitol. 40: 937-944.

Roberts, L.S and Janovy, J. (2009): Foundations of Parasitology, $8^{\text {th }}$ edition. McGraw-Hill International Editions, Boston. pp. 502.

Saleh, R.A. (2010): Parasitological survey on African sharptooth catfish (Clarias gariepinus). M. V. Sc. thesis, Faculty of Veterinary Medicine, Assiut University.

Saleh, R.A. (2015): Myxosporidian infection in Oreochromis niloticus and Clarias gariepinus. $\mathrm{Ph}$. D. thesis, Faculty of Veterinary Medicine, Assiut University.
Shoaibi, O.B.; Mousavi, H.A. and Sharifpour, I. (2010): Ocurrence and histopathology of Ascocotyle tenuicollis metacercaria in gill of platyfish (Xiphophorus maculatus) imported to Iran. Iran J. Fish Sci. 9: 472-477.

Skinner, R.H. (1982): The interrelation of water quality, gill parasites and gill pathology of some fish from South Biscayne Bay Florida. Fish. Bull. 80:269-280.

Sterud, E.; Harris, P.D. and Bakke, T.A. (1998): The influence of Gyrodactylus salaris Malmberg, 1957 (Monogenea) on the epidermis of Atlantic Salmon, Salamo salarL. and, Salvelinus fontinalis (Mitchill): experimental studies. J. Fish Dis., 21: 257-263.

Tachia, M.U.; Omeji, S. and Odeh, I. (2013): A survey of ectoparasites of clarias gariepinus caught from university of agriculture research fish farm, Makurdi. J. research forest. wildlife environ. 4: 30-37.

Uruku, M.N and Adikwu, I.A. (2017): Seasonal prevalence of parasites of clariids fishes from the lower Benue River, Nig. J. Fish. Aqua. 5(2): 11-19.

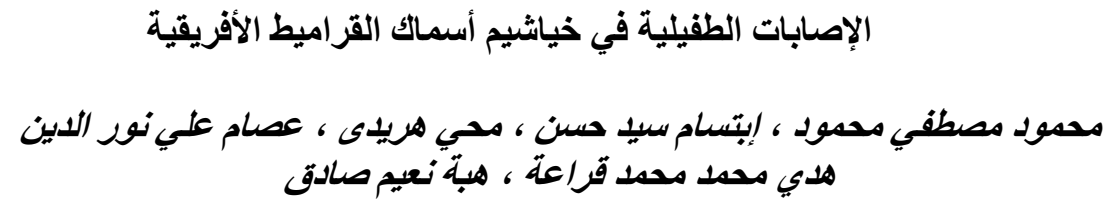

E-mail: mahmoud88@aun.edu.eg; mahmoud88@hotmail.com Assiut University web-site: www.aun.edu.eg

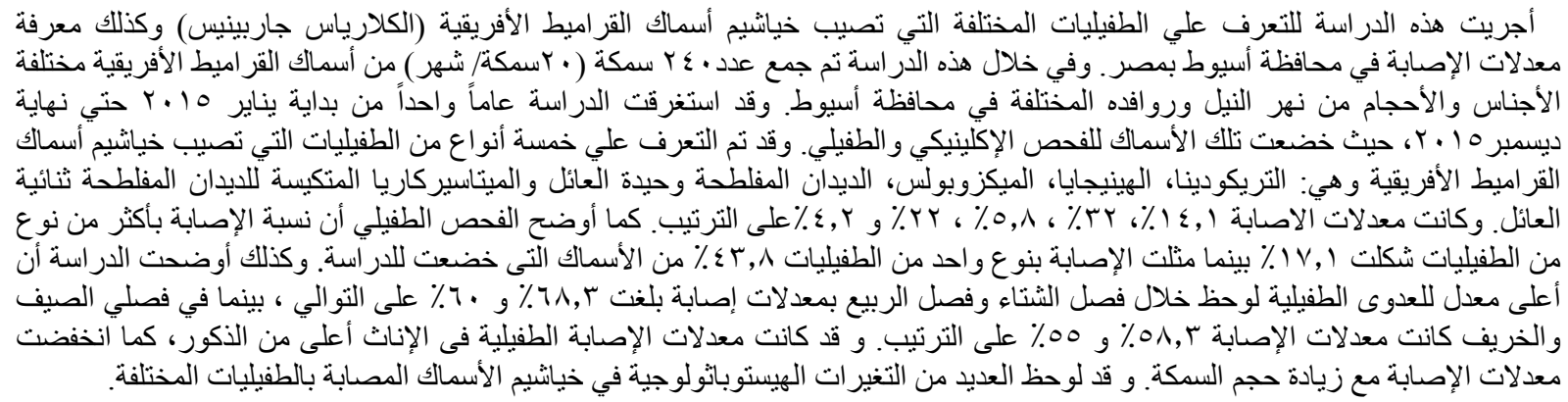

